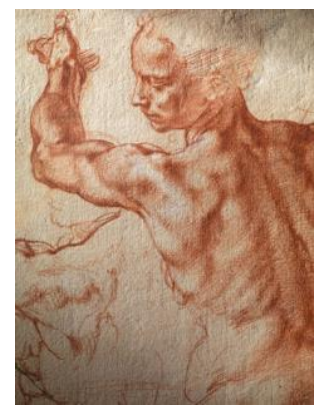

Intelligere, Revista de História Intelectual

no 8, dez. 2019

ARTIGOS - ARTICLES

\title{
Ideias de Ciência e Progresso - dos Tsares à Era Soviética
}

\author{
Gildo Magalhães ${ }^{1}$ \\ Professor Titular do Departamento de História \\ Diretor do Centro de História da Ciência - Universidade de São Paulo \\ gildomsantos@hotmail.com
}

Como citar este artigo: Magalhães, Gildo. "Ideias de Ciência e Progresso - dos Tsares à Era Soviética", Intelligere, Revista de História Intelectual, no8, pp. 40-61. 2019. Disponível em <http://revistas.usp.br/revistaintelligere>. Acesso em $\mathrm{dd} / \mathrm{mm} /$ aaaa.

Resumo: Apresenta-se uma breve exposição de ideias ligadas ao progresso científico na área que constituiu o Império Russo e posteriormente a União Soviética entre os séculos 18 e 20, com especial destaque para aspectos das ciências naturais ainda pouco explorados.

Palavras-chave: Rússia, progresso, ciência e tecnologia.

\section{Ideas of science and progress - from Tsares to the Soviet Era}

Abstract: A short exposition of ideas connected with scientific progress in the area that constituted the Russian Empire, and later Soviet Union, between the $18^{\text {th }}$ and $20^{\text {th }}$ centuries, with emphasis on aspects of natural sciences that have remained little studied.

Keywords: Russia, progress, science and technology.

\footnotetext{
${ }^{1}$ Gildo Magalhães é Professor Titular do Departamento de História da Faculdade de Filosofia, Letras e Ciências Humanas da Universidade de São Paulo, professor de História colaborador do ISCTE - Instituto Universitário de Lisboa) e da Universidade de Lisboa (Centro de Filosofia da Ciência). Dirige o Centro Interunidades de História da Ciência da Universidade de São Paulo.
} 


\section{Panorama da produção científica russa no período pré-Revolução de Outubro}

Apesar de haver um abismo entre a massa de camponeses analfabetos e as classes mais favorecidas, houve algum prestígio oficial para a ciência e a tecnologia no Império Russo, ao menos desde o início do século XVIII. Em 1724 o tsar Pedro, o Grande, que se interessava pela construção naval, pelas ciências e artes, criou a Academia Russa de Ciências e a Universidade de São Petersburgo, instituições às quais se acrescentou a Universidade de Moscou, fundada em 1755 por Mikhail Lomonosov, cientista de projeção internacional.

Estas iniciativas do governo russo atraíram cientistas europeus de grande renome para trabalhar nestes centros, como foi o caso do famoso matemático alemão Leonhard Euler. Os intercâmbios científicos com países na dianteira da ciência e tecnologia, como a Alemanha e a França, foram mais intensificados na segunda metade do século XIX. O resultado foi o estabelecimento de uma certa tradição de pesquisa na Rússia que, por volta dessa época, chegou a influenciar outros centros europeus, como exemplificado na matemática com a geometria de Nikolai Lobatchevsky e a teoria da estabilidade dinâmica de Aleksandr Lyapunov, na eletricidade com os trabalhos de indução eletromagnética de Heinrich Lenz e as invenções de lâmpadas elétricas incandescentes e o pioneirismo russo na transmissão de ondas de rádio de Pavel Yablotchkov, nos estudos de embriologia e evolução de Karl von Baer e na biologia com a teoria da simbiogênese de Konstantin Mereshkovsky, em que espécies não se destroem, mas uma espécie incorpora a outra, com um resultado cooperativo..

O Império Russo conheceu um surto maior de industrialização no final do século XIX, quando o governo atendeu apelos de intelectuais nacionalistas como o famoso químico Dmitri Mendelêiev, um dos responsáveis pela criação da tabela periódica dos elementos. Seu livro Princípios de Qquímica foi um sucesso, sendo traduzido para diversas línguas, e nele havia uma forte exortação para que os jovens aprendessem ciência e levassem o país a progredir social e economicamente. $\mathrm{O}$ desenvolvimento industrial foi realizado com o apoio de uma parte mais progressista da elite, liderada pelo ministro Conde 
Sergei Witte, que enfatizou o desenvolvimento da metalurgia, a extração de petróleo e os transportes. A malha ferroviária russa foi igualmente muito incrementada pela sua ação e se estendeu da Europa até o Pacífico, com a construção da ferrovia transiberiana. Nessa época foram organizadas escolas técnicas para apoiar a industrialização, provendo uma melhoria na capacitação do crescente proletariado urbano a trabalhar nas fábricas.

Graças a essa base, a ciência russa, apesar das tensões sociais internas, teve algum papel de destaque na Europa e ganhou um prêmio Nobel em Medicina já em 1904 pelos estudos de reflexos condicionados de Ivan Pavlov e outro Nobel de Medicina com as descobertas sobre imunologia de Ilya Metchnikov em 1908. Os estudos de mecânica dos fluidos também estavam bem avançados na Rússia graças a trabalhos como os de Nicolai Jukovski. Pode-se comparar esta situação com o atraso bem maior na mesma época do Brasil no Império, sem universidades e com pouca tradição de pesquisa científica e tecnológica.

Não deixa de ser sintomático da existência de tradição científica russa que um eminente arquiteto político da revolução soviética como Lênin tenha dedicado um livro, Materialismo e Empiro-criticismo (1908), para discutir (independentemente de seus acertos ou erros), questões científicas e epistemológicas de física e biologia numa visão filosófica materialista. Lênin dedica um capítulo para discutir a revolução científica, ainda em curso, envolvendo a teoria eletromagnética e, mais amplamente, a atomística. Sua crítica ao positivismo e idealismo, bem como a físicos como Ernst Mach mostra que seguia com atenção os debates que se travavam nas ciências naturais e na epistemologia. Em especial, Lênin dedica parte significativa dessa obra para tratar do elétron, de sua massa e energia, já levando em conta aspectos da teoria da relatividade, adiantados por Henri Poincaré e outros.

\section{$O$ incipiente poder soviético, a reorganização da economia e o desenvolvimento científico e tecnológico}

A reorganização da economia após a revolução soviética foi um processo difícil e que teve sucessos e fracassos em meio à terrível guerra civil e 
seus efeitos, logo após 1917, além de sofrer a hostilidade externa ao novo regime. A sobrevivência econômica mais imediata da União Soviética após a vitória do exército vermelho foi conseguida recorrendo-se à NEP, "nova política econômica" mais tolerante do que a imposta pelo radicalismo do comunismo de guerra. A NEP e as políticas seguintes dos soviéticos enfatizaram a formação científico-técnica e deram prioridade para a eletrificação do país, como pré-requisitos para uma arrancada industrializante e desenvolvimentista em geral. Um retrato das dificuldades dessa época em conciliar a educação socializante de orientação soviética com democracia e iniciativa individual, apesar da falta geral de recursos $\mathrm{e}$ dos entraves burocráticos do Partido Comunista, está no extraordinário testemunho deixado por Anton Makarenko em seu instigante livro Poema Pedagógico.

De início, a prioridade soviética maior foi para diminuir a enorme taxa de analfabetismo do povo. Aos poucos, o ensino secundário foi estendido para novas camadas da população, incluindo um grande número de escolas técnicas e de educação para adultos, que rompendo um preconceito tradicional na sociedade russa admitiram um contingente feminino significativo. Trabalhadores tiveram acesso ao ensino superior em faculdades técnicas e aumentou o número de universidades, onde se buscou um conteúdo de ensino de nível elevado. O número de alunos universitários praticamente triplicou durante o primeiro plano soviético quinquenal entre 1928 e 1932, passando de 159.757 para 469.215, enquanto que o número de cientistas com pósgraduação nesse mesmo período aumentou mais de dez vezes, de 1.548 para 16.500 .

Cientistas jovens e brilhantes que eram simpatizantes do comunismo e de uma sociedade mais justa, como prometido pelo ideal soviético, se esforçaram em contribuir para o sucesso do novo regime. Um resultado de preocupações ideológicas na URSS e que, apesar de sua importância é um aspecto em geral pouco mencionado, é a influência no desenvolvimento da ciência natural soviética, em especial na física, das discussões sobre a viabilidade do socialismo enquanto expressão do coletivismo, em que entidades subatômicas foram tratadas como agrupamentos coletivos. 


\section{A física e a biologia coletivistas}

No século XIX, no começo dos movimentos revolucionários de esquerda, "coletivismo" era uma palavra de ordem empregada pelos anarquistas (como Bakunin), em oposição ao "comunismo" de Marx e Engels. Depois da revolução russa o conceito de coletivismo foi apropriado por Stálin e o kolkhoz surgiu na reforma agrícola de 1930 como uma empresa coletivistaestatal, mas cujos resultados econômicos e sociais foram sabidamente desastrosos.

$\mathrm{Na}$ física a preocupação com o coletivismo foi coincidentemente uma iniciativa de cientistas engajados ou simpatizantes do comunismo (vários deles judeus), como Igor Tamm, Yakov Frenkel (prêmio Nobel), Lev Landau (também prêmio Nobel, que esteve mais perto dos trotskistas) na URSS. A pergunta inicial que se fez na física a esse respeito foi relativa ao que seria a liberdade dos "elétrons livres", principalmente nos metais, mas também em outros materiais.

Frenkel na década de 1920 foi um ativista político que observou de perto as manifestações de rua de trabalhadores, interessando-se por observar como eram desfeitas pelas barreiras policiais ou ao contrário penetrando e cortando estas barreiras, o que o levou a fazer analogias com os elétrons sendo espalhados ou passando ilesos pelas grades cristalinas dos átomos dos materiais. Ele propôs a esse respeito modelos matemáticos que consideravam as "lacunas" (ausências) de elétrons como se fossem equivalentes a partículas. Assim as lacunas se deslocariam e recombinariam, hipótese que se revelou frutífera e foi mesmo essencial para o desenvolvimento teórico da física dos semicondutores. Essas coletividades tinham um comportamento em conjunto bem diferente do que exibiam partículas individuais ou do que seria de se esperar agregando-se individualidades em conjuntos. As lacunas deram origem a novas hipóteses de outras partículas, como os fônons. Mais tarde, as ideias de coletivismo foram utilizadas na física dos plasmas nucleares (como no tratamento dado por Landau e pelo norte-americano David Bohm), por se tratar de entidades também constituídas por multicorpos. 
A questão da liberdade da partícula num meio coletivo remetia imediatamente à recente disputa política na Rússia entre bolcheviques e mencheviques. A disciplina e subordinação dos membros individuais à organização do partido bolchevique se contrapunham a uma maior liberdade individual do menchevique. Se o movimento das partículas apresenta um resultado coletivo, como conciliar padrões desse coletivismo final a partir da liberdade individual das partículas, cujo comportamento era bem conhecido? Num plasma, por exemplo, as partículas sentem pequeníssimas interações simultâneas resultantes de muitas outras partículas remotas. Foi estudando esse problema que na década de 1940, David Bohm achou uma solução particular bem-sucedida de uma equação para o plasma. Pouco depois ele foi indiciado como comunista pelo macarthismo nos EUA e veio exilado para a o Brasil, mais precisamente para a Universidade de São Paulo (onde permaneceu de 1951 a 55), partindo depois e vindo a ganhar o prêmio Nobel.

Os enfoques coletivistas posteriormente entraram na ciência também em campos diferentes do nuclear, como na física de baixas temperaturas, tendo, porém, sido extirpados de seu componente ideológico mais explícito do início, trocado por uma física mais "neutra", de forma que são hoje empregados por físicos sem nenhuma tendência socialista, ou política, explícita. No entanto, há quem considere que o conceito de coletivismo na URSS teve maior impacto na física daquele país e em geral do que qualquer outro aspecto da ideologia socialista, como por exemplo o materialismo dialético.

Outros exemplos de ciência comprometida com ideias soviéticas apareceram nos estudos de biologia. Para entender melhor as controvérsias resultantes, é necessário retroceder aos trabalhos teóricos e práticos do embriologista alemão Hans Driesch (1867-1941), que ao final do século XIX fez descobertas surpreendentes sobre a individualização de células para formar organismos diferenciados. Driesch (em 1891) separou mecanicamente dois blastômeros (células em estágio inicial de multiplicação) dum embrião de ouriço marinho e de cada um dos bastômeros observou que se desenvolvia o embrião inteiro (experiências mais atuais mostram que a retirada de 1/4 a 1/3 do citoplasma do zigoto ainda resultam num embrião normal). Driesch sugeriu então dois conceitos: 
- Equipotencialidade: todos elementos (células) dum embrião têm o mesmo potencial morfogenético.

- Equifinalidade - um mesmo resultado final do desenvolvimento pode ser atingido por caminhos totalmente diferentes.

A conclusão de Driesch foi que o destino do elemento é uma função de sua localização dentro do todo. Filosoficamente, sua teoria é um tipo de vitalismo, que tem a ver com a noção de causa final (teleologia), contrapondose ao conceito então vigente de desenvolvimento mecanicista, formulado por Wilhelm Roux. O importante é que Driesch demonstrou que durante a embriogênese todas reorganizações celulares são determinadas primordialmente pela localização das células particulares dentro do espaço dum embrião em desenvolvimento, ao invés de propriedades específicas de tais células, algo que só foi retomado para valer com os estudos mais atuais das células-troncos.

Esta importante questão poderia ser expressa como mais um reflexo do que ocorreu na física coletivista, ou seja, das relações entre indivíduos, no caso as células, e uma coletividade, como a dos tecidos e órgãos. Como a Alemanha foi o centro científico mundial nas últimas décadas do século XIX e nas primeiras do século XX, não é de admirar que muitos cientistas da futura URSS tivessem conhecido os trabalhos alemães, dentre os quais os de Driesch e assim também tenham sido influenciados pela oposição dialética entre partículas e coletividades evocada anteriormente, ainda que o campo científico associado fosse a biologia e não a física.

Ervin Bauer foi um brilhante jovem teórico da biologia geral, que acabou sua vida (provavelmente) em 1937, nos campos de extermínio de Stálin. Sua compreensão do fenômeno da vida foi influenciada pelas ideias filosóficas de Driesch e pode ser resumida a partir da sua formulação de dois princípios originais:

- Princípio do desequilíbrio estável - "nenhum sistema vivo está em equilíbrio, e sobrevive trabalhando contra o equilíbrio de acordo com as leis físicas e químicas exigidas". Daí concluiu que o 
desequilíbrio deve ser manifestado em todos os níveis dum sistema vivo, começando no molecular.

- Princípio da tendência histórica para aumento do trabalho externo "apenas sistemas vivos exibem um processo estruturado e dirigido, apontando para um aumento no estoque de energia livre do sistema, isto é, em seu desequilíbrio estável”.

Numa aplicação direta desses princípios à biofísica, o estado de desequilíbrio máximo duma molécula corresponde a seu estado de maior excitação eletrônica, quando a transição para um estado menos excitado é acompanhado pela emissão de um fóton de luz.

Para entender melhor essa linha de pesquisa, é oportuno detalhar os trabalhos de Alexander Gurvitch. Formado em medicina em Munique (1897), trabalhou nas universidades de Estrasburgo e Berna; em 1905 voltou para a Rússia como professor de anatomia, histologia e embriologia. A partir de 1930 foi pesquisador e desenvolveu sua teoria do campo biológico vetorial; Gurvitch renunciou aos seus postos acadêmicos em 1948, em protesto contra os métodos administrativos do todo-poderoso e arbitrário ministro de Stálin, Lysenko, e continuou em casa os estudos de divisão celular até sua morte, cercado por seus colaboradores e alunos.

Gurvitch estudou os processos biológicos ao nível molecular. Ele já havia estudado $(1904,1905,1908)$ ovos de anfíbios e equinodermos e descobriu que a centrifugação destruía todas estruturas visíveis, mas os processos básicos de separação e formação de blástulas continuavam. Daí concluiu que para manter essa estrutura intracelular invisível era preciso uma energia metabólica e que há dois tipos distintos de associações moleculares possíveis em sistemas vivos: i) estáveis, constituindo estruturas visíveis e invisíveis nas quais as moléculas têm ligações químicas comuns; II) instáveis, sem aquelas ligações, mas onde a associação se mantém por um influxo contínuo de energia.

São ideias semelhantes às de Bauer. Gurvitch resolveu testar experimentalmente sua teoria e confirmou que todos animais e plantas 
estudados mostravam um pequeno surto de radiação durante a divisão (por mitose) tanto em casos de degradação metabólica (resfriamento abrupto ou leve narcose) quanto mecânica (centrifugação ou corrente alternada fraca). Em 1923, Gurvitch descobriu que organismos vivos emitem fótons de alta energia na faixa do ultravioleta e que essa emissão é um pré-requisito para que ocorra a mitose (divisão) celular, chamando-a de "radiação mitogenética". Em sua "experiência da cebola", ele verificou que a mitose na região apical da cebola era acompanhada pela emissão de uma radiação fraca, na faixa do ultravioleta. Essa radiação é de muito baixa intensidade, mas na presença de fatores externos (irradiação, aquecimento, resfriamento, esforço mecânico, compostos químicos, etc.) ela é muito amplificada, de forma parecida com um laser. Gurvitch verificou ainda que durante o desenvolvimento embrionário a radiação espontânea diminui, ao passo que aumenta muito a radiação mitogenética. Devido a esses resultados experimentais, formulou a hipótese de que cada célula viva produz um "campo" vetorial elementar, que se projeta para além da fronteira estrutural da célula. Assim que a célula se divide, o campo também se divide. As propriedades mais marcantes do campo celular teorizado por Gurvitch são sua anisotropia e que o campo total é a síntese (soma) do campo próprio da célula e de todas as demais contribuições. Diversas experiências confirmaram que, mesmo na ausência duma interação química entre duas populações celulares, se houver um canal físico entre elas (por exemplo, óptico), a excitação em uma delas é acompanhada por mudanças fisiológicas na outra.

$\mathrm{Na}$ biologia atual, tem-se cada vez mais reconhecido que as reações biológicas decorrem como processos oscilatórios não-lineares. Todos os colágenos e muitas proteínas do plasma sanguíneo têm estruturas fibrilares helicoidais, em princípio capazes de transferir ondas eletromagnéticas a distâncias longas, o que poderia ser a base de uma comprovação experimental da realidade dos campos de Gurvitch. Nesse caso, os elementos celulares de tecidos conjuntivos desempenham o papel de transdutores, decodificadores e amplificadores dos sinais - e todos sistemas vivos possuem tecidos conjuntivos ou seus análogos, mesmo que não tenham sistemas circulatórios ou nervoso

Gurvitch aplicou o conceito de campo também para a esfera 
neurofisiológica (1929). Sua análise se baseia no estudo do córtex cerebral como um todo, diferentemente da teoria neurônica clássica, que se concentra quase só nas sinapses. Concluiu que há uma conexão contínua entre as esferas psíquica e somática e que, portanto, os elementos psíquicos estariam presentes em qualquer estágio do desenvolvimento do embrião.

É significativo que os primeiros biólogos da corrente filosófica do início do século XIX conhecida como Naturphilosophie (e posteriormente combatida e desacreditada com sucesso pela filosofia da ciência de tendência positivista) tenham lidado com o problema de uma ordenação implicitamente evolutiva que emanaria da própria natureza, opondo-se aos argumentos de evolução baseada no acaso, que foram amplamente aceitos no caso do darwinismo. Gurvitch achava que o gen não pode explicar a morfogênese, porque é caracterizado por parâmetros químicos; em contrapartida, o embrião não se desenvolve como uma rede de conexões causais separadas, mas é responsável como um todo pelo resultado final.

Esta conclusão não colocava Gurvitch como opositor da genética mendeliana, mas foi elaborada por que ele a entendia como uma ordenação do processo vital que se contrapunha à ideologia do darwinismo. Esta visão parece ter sido o real motivo pelo qual a radiação mitogenética descoberta por Gurvitch foi desautorizada por cientistas da Fundação Rockfeller em meados do século XX, mas suas experiências e ideias foram retomadas com êxito na Alemanha nas últimas décadas por grupos de biofísicos, com melhor aparelhamento do que se dispunha na União Soviética. Esses trabalhos estão muito relacionados tanto com fenômenos de geração como de morte das células, inclusive no estudo do câncer.

Nessa corrente da biologia soviética nota-se também a forte influência de Vladímir Vernadsky, fundador da biogeoquímica e um dos mais eminentes cientistas soviéticos, reconhecido com essa qualidade tanto na URSS quanto no Ocidente. Vernadsky desenvolveu, juntamente com Teilhard de Chardin, seu colega em Paris na década de 1920, o conceito de "noosfera" como resultado da tendência da biosfera de, a partir do surgimento do homem, contar com 
uma nova e poderosa força geológica, cuja energia transforma a face do planeta.

Provavelmente aproveitando as teorias de Bauer, Vernadsky dizia que o consumo de energia aumenta historicamente de forma obrigatória, o que permite a obtenção de energia livre cada vez mais "estruturada". Um significado maior poderia ser acrescentado pelo estudo do conceito cósmico de uma biosfera ainda mais ampla do que a do planeta, em que se reconhece que o homem já se expandiu pelo espaço extraterrestre. Vernadsky, assim como Mendelêiev antes dele, defendeu veementemente o progresso tecno-científico e se tornou uma figura politicamente proeminente durante o regime soviético.

$\mathrm{Na}$ filosofia de Vernadsky, do ponto de vista da seleção natural, o homem seria uma espécie pouco apta a sobreviver, sendo mais fraco e como um "macaco nu", mas na verdade é a espécie mais adaptada a condições ambientais instáveis, o que é fundamental para a evolução. Foi devido ao uso da razão pelo homem que sua presença se impôs às demais formas de vida, o que o levou a criar a linguagem articulada, a viver em sociedades complexas e enfim, ao contrário das demais espécies, a fabricar uma cultura altamente elaborada e transmissível sem ser de forma genética. É devido à infância prolongada que o homem desenvolve sua inteligência e criatividade, que o capacitam a assimilar e desenvolver tecnologias, desde o fogo até as espaçonaves. A Terra e sua biosfera são para o homem o oposto de um ambiente fixo e a evolução tem nela agido para gerar novas espécies que sucedem outras extintas sem tanta versatilidade para transformar a biosfera.

Assim, para Vernadsky é a própria biosfera (que inclui desde camadas geológicas das rochas, até as camadas elevadas da estratosfera) que está continuamente em evolução, e não somente as espécies. Em consequência, o pensamento humano criativo, ou como ele chama, "científico", é por ele visto como uma nova "força geológica" na biosfera, qualitativamente diferente das forças físico-químicas e biológicas anteriores, o que passou a dar à biosfera o caráter distinto de "noosfera", através do fenômeno do conhecimento.

A organização interna da biosfera para Vernadsky é que dita a evolução - e aqui se aplica apenas em sentido de metáfora a imagem do automóvel que alguns têm usado: o "motor" da evolução seria a direcionalidade ("progresso") 
e a variação genotípica sua "direção" (onde intervém o acaso na forma de buracos na estrada, etc., o que faz variar a "condução"). O homem, porém, chegou num ponto em que intervém em ambos elementos da "dirigibilidade". Sua liberdade é a expressão de uma qualidade tendencial presente também na primeira forma de vida celular, e se passaram muitas épocas até que pudesse refletir sobre isso, ou seja foi preciso surgir a noosfera.

As hipóteses de Gurvitch reforçam as teorias biológicas de Bauer e Vernadsky, de que a evolução da biosfera como um todo segue a direção de um aumento do estoque de energia livre responsável por seu desequilíbrio estável. As espécies mais recentes deveriam ser capazes de realizar mais trabalho externo em seu ciclo vital do que as espécies anteriores. A realização de trabalho necessita de consumo de energia e, de fato, o consumo energético em relação à massa "viva" durante o ciclo vital tem crescido milhares de vezes desde os celenterados até os primatas, sendo para o homem no mínimo uma ordem de grandeza maior do que para os primatas.

Dessa forma, o aparecimento da humanidade é um novo salto num processo de desenvolvimento do planeta - como se o planeta todo fosse um embrião, ou ainda como um processo de evolução da biosfera como um todo e do homem em particular, que se tornou a força dominante nela. Os aperfeiçoamentos tecnológicos e da organização social derivam de poderes mentais crescentes - essa noosfera (uma biosfera sujeita à razão humana consciente), que nada mais expressam do que o princípio histórico da maior energia livre.

\section{A industrialização acelerada de Stalin e impactos na criação de novas tecnologias}

A ênfase do primeiro plano quinquenal (1928-1932) de Stálin foi investir na indústria pesada. A industrialização acelerada acabou se revelando essencial para quando depois a União Soviética teve de se preparar num prazo relativamente curto para a difícil guerra que acabou travando contra a Alemanha nazista. O esforço máximo do planejamento estatal era voltado para realizar um enorme salto tecnológico, e para conseguir isso Stálin apelou para a 
indústria norte-americana, cujo sucesso era por ele reconhecido. Em particular, o "gerenciamento científico" introduzido pelo taylorismo assim como a prática do fordismo nas linhas de montagem exerceram um forte apelo para que a Rússia admitisse uma aparente incoerência como a de adotar técnicas americanas de produção.

A explicação para isso é que os líderes comunistas, inclusive Lênin e Trotsky, acreditavam que a alta produtividade e qualidade atingidas nos EUA com o emprego dos métodos científicos de manufatura para a siderurgia, a geração hidroelétrica e a fabricação em massa de automóveis também poderiam ser alcançadas no regime soviético. Acreditavam ainda na legitimidade da iniciativa porque no estado soviético essas técnicas não acabariam por incorrer na desvantagem de explorar economicamente a mãode-obra do operariado e outras contradições do sistema capitalista de produção.

Foi assim que a Ford instalou um moderno sistema de geração hidroelétrica no rio Dnieper e, aproveitando essa energia, foi construída uma enorme fábrica de caminhões e tratores na Stalingrado já em 1928. Outras fábricas se seguiram em diversas localidades e em 1930 foi inaugurada uma linha de montagem de automóveis Ford modelo A. Os resultados ficaram aquém do planejado, mas os vários anos de trabalho de técnicos e engenheiros americanos em solo russo foram de certa forma uma das razões do sucesso da industrialização forçada.

No entanto a repressão brutal do período chamado de Grande Terror, desencadeado por Stálin ainda na década de 1930 foi fatal e solapou muitos ganhos econômicos, científicos e tecnológicos que haviam sido obtidos até então, pois juntamente com políticos e intelectuais um número enorme de cientistas e técnicos foi enviado para trabalhos forçados ou simplesmente exterminado, ao serem delatados supostamente como contrarrevolucionários, ou até por serem judeus. Na imensa maioria das vezes tratava-se de pessoas que eram simpatizantes ou até mesmo militantes da causa soviética que protestaram exigindo condições mais democráticas. 


\section{As lideranças e o desenvolvimento das ciências sociais}

A história, a filosofia e a sociologia foram campos em que se impôs uma visão oficial do Partido Comunista, de tendência dogmática e unilateral. É significativo o episódio do comparecimento em 1931 para o II Congresso Internacional de História da Ciência e Tecnologia, em Londres, da delegação soviética chefiada por Nikolai Bukharin e com nomes de peso como o físico Abram Ioffe e o biólogo Nikolai Vavilov. Os trabalhos por eles apresentados foram reunidos num livro publicado em inglês que se tornou um clássico, Science at the crossroads. Mas nenhum trabalho desse grupo causou tanta comoção e controvérsia como o do físico e historiador da ciência Boris Hessen, que expôs sua interpretação da base capitalista material, econômica e social como o apoio às ideias filosóficas e científicas da mecânica de Newton.

$\mathrm{Na}$ chamada "tese de Hessen", sua interpretação marxista do trabalho de Newton afirmava que a formulação da mecânica clássica dependeu do contexto sócio-econômico da Inglaterra no século XVII e era uma resposta às necessidades tecnológicas do capitalismo mercantil e manufatureiro, então emergente. Newton negava que o movimento era inerente à matéria e assim retinha um papel para Deus como o primeiro motor do universo. Para Hessen, essa mecânica era alicerçada numa filosofia da ciência mediada pela consciência de classe burguesa adotada por Newton. Este trabalho historiográfico tem sido considerado o início da chamada corrente externalista da história da ciência, a que se agregaram depois os trabalhos do americano Robert Merton, do alemão Edgar Zilsel e do inglês Joseph Needham. A “tese de Merton” (1938) retoma a de Hessen e vê ligações entre o protestantismo inglês e a institucionalização da ciência. A “tese de Zilsel”, ou do "artesão e intelectual” (1942) é de que o progresso da tecnologia mecânica e o rearranjo social do capitalismo emergente no fim da Idade Média possibilitaram o surgimento da ciência moderna, graças à aproximação entre artesãos, professores universitários e humanistas do Renascimento. Já a tese de Needham (1954) é de que a China não teve uma revolução científica como no Ocidente devido à sua organização social do conhecimento e às suas relações de produção, em que a burguesia não tinha o poder. 
A teoria contrária à do externalismo diz que a ciência é basicamente um empreendimento intelectual isolado de circunstâncias sociais, políticas e econômicas. O externalismo de Hessen foi acusado de ser muito radical e até mesmo grosseiro, sujeito à doutrinação de esquerda, enquanto que o internalismo enfatizou características da ciência tais como sua continuidade e progressividade, sendo em geral mais aceito do que o externalismo. Talvez mais relevante e pouco lembrado é que as discussões se deram num contexto de questões práticas, notadamente a da validade do planejamento da ciência pelo Estado. Um debate historiográfico como esse entre externalismo e internalismo acabou envolvendo a importante questão de como deveria ser a política científica e tecnológica de cada nação. A controvérsia ressurgiu com relação à interpretação da Revolução Científica e foi mais agudo no período entre o fim da $2^{a}$ Guerra Mundial e o fim da Guerra Fria. A questão se originou nesse contexto com relação à interpretação da Revolução Científica do século XVII e um desdobramento da divergência foi precisamente se o progresso científico se fazia de forma contínua ou através de uma transformação drástica de visões de mundo, ou "revolução". Desta forma, a oposição entre o externo e o interno na história da ciência se transformou num debate entre a historiografia de esquerda, principalmente a de veia marxista, e visões mais conservadoras. A queda do Muro de Berlim e a dissolução das repúblicas socialistas soviéticas, com o consequente fortalecimento das políticas neoliberais, fez com que diversos historiadores proclamassem o fim das ideologias e das explicações que relacionavam as dimensões da base com a superestrutura, o que afetou também a historiografia da ciência, acentuando a preferência pela história internalista.

Mesmo após a projeção internacional desse ardoroso defensor do marxismo-leninismo, Hesse sucumbiu aos expurgos stalinistas e foi fuzilado como traidor, assim como Bukharin.

Há críticas duras à intromissão da política soviética nas ciências sociais feitas nas décadas de 1930 e 1940 pelo já citado cientista Vladimir Vernadsky, que acusou a União Soviética de ter substituído o pensamento filosófico genuinamente crítico e questionador por um jargão que se pretendia marxistaleninista, mas era apenas um discurso oficial, conformista e estéril. Apenas por 
ser um nome tão reconhecido na ciência, Vernadsky foi poupado, embora muitos de seus auxiliares e familiares não tivessem tido esta sorte.

Neste clima ditatorial os cientistas sociais não podiam expressar livremente suas opiniões. Houve um momento, porém, em que toda a nação, inclusive cientistas e artistas dissidentes, se uniu de forma patriótica em torno de Stálin e em defesa do regime soviético, e este momento foi a Segunda Guerra Mundial. Após esse intervalo da guerra, a condução geral da ciência continuou de forma errática e despótica, para o que pesou o despotismo na condução política geral da ciência stalinista por Trofim Lysenko. Suas experiências como agrônomo derivavam de interessantes práticas de hibridização vegetal de Ivan Mitchurin e inicialmente Lysenko teve sucessos como a colheita de trigo plantado no inverno. É notável que, depois da denúncia dos crimes de Stálin e a exemplo de nações ocidentais, a ação administrativa de Lysenko seja hoje condenada até dentro da Rússia, mas que, pelo contrário, ela seja julgada de forma independente de suas teorias biológicas da herança de caracteres adquiridos. Com a promessa de aumentar a produtividade e compensar os fracassos da coletivização, havia uma disputa ideológica no que passa por ser apenas mais uma versão de evolução lamarckista, mas que também trata da questão fundamental de como um indivíduo pode influenciar a geração de uma coletividade - esta é uma forma de entender o problema da herança de caracteres adquiridos como formação de novas espécies.

Lysenko, na sua trajetória na política stalinista, perseguiu colegas e atrasou o progresso científico na URSS, mas suas experiências biológicas ainda não foram devidamente analisadas pela história da ciência. Se nada houvesse de interesse científico nesta questão, seria difícil explicar porque a teoria de Mitchurin e Lysenko foi defendida por um geneticista tão importante quanto o britânico John Haldane, ainda que este fosse comunista. Este é um terreno sensível porque muitas pessoas pensam erroneamente que criticar a teoria darwiniana da evolução significa defender o criacionismo religioso na sua forma fundamentalista, isto é, a que toma literalmente a interpretação das escrituras sagradas cristãs. As ideias sobre herança de caracteres adquiridos mereceram uma experimentação intensiva no âmbito da epigenética e desde a 
década de 1960 surpreendentemente vêm ganhando novos adeptos dentro da Rússia e o apoio mesmo de alguns biólogos fora dela, como no caso espetacular de criação de raposas adaptadas ao ambiente doméstico humano, domesticação essa que tem se mantido espontaneamente entre os descendentes das primeiras raposas treinadas, como se fossem cães.

\section{As dificuldades tecnológicas da União Soviética}

Com o término da Segunda Guerra Mundial os aliados, principalmente os EUA e a União Soviética, se beneficiaram da derrota nazista graças à captura e colaboração de importantes nomes da ciência alemã. Dentro da União Soviética, em especial a Rússia e a Ucrânia tinham uma base científicotecnológica que podia aproveitar bem a cooperação dos novos cérebros trazidos de fora. Além disso, havia uma plêiade de cientistas nacionais que estava no primeiro plano em termos mundiais, muitos dos quais foram laureados com o prêmio Nobel, como Alexei Abrikosov, Piotr Kapitza, Lev Landau, Igor Tamm e Nikolai Semyonov.

A atmosfera de patriotismo e defesa da União Soviética continuou, mesmo após o início da Guerra Fria, e o esforço coletivo resultante explica o sucesso da fabricação de armas nucleares e da dianteira na corrida espacial neste item o satélite Sputnik e o primeiro vôo extraterrestre de Yuri Gagárin causaram forte comoção e um sentimento de inferioridade técnica no Ocidente, que começou a mobilizar recursos enormes para tentar mudar o jogo de poder, o que foi conseguido, como demonstrado pelo sucesso do projeto aeroespacial Apolo dos EUA.

Um historiador americano contemporâneo da ciência, Loren Graham, estudou detidamente os motivos do fracasso da Rússia em várias épocas (imperial, soviética e atual), sem conseguir transformar seu rico cabedal de talentos científicos e tecnológicos numa modernização comparável à dos países mais avançados. Embora Graham seja um apologista do liberalismo capitalista e ferrenho anticomunista, alguns fatores levantados por ele parecem se aplicar para explicar o atraso, e em geral não houve a passagem necessária do estágio de invenção para o de difusão dos inventos e descobertas científicas na União 
Soviética e na Rússia, em particular. Entre as razões para isso, se destacam a falta de financiamento e apoio (estatal ou privado), falta de diálogo democrático e de concorrência entre diferentes ideias e modelos, de pouco incentivo à inovação e, certamente, contribui significativamente o peso da burocracia e da corrupção no aparelho de Estado.

\section{Algumas contribuições da ciência soviética que influenciaram novas tecnologias e serviços}

Istvan Hargittai escreveu um livro com biografias de quatorze cientistas soviéticos, muitos dos quais são pouco conhecidos hoje tanto em seu país quanto fora dele. No passado a Cortina de Ferro poderia ser invocada para explicar esse desconhecimento, apesar de metade desses cientistas ter ganho o prêmio Nobel e de todos terem gozado de reconhecimento oficial, na forma de medalhas de Heróis do Trabalho Socialista, prêmios Stalin e terem entrado na prestigiada Academia de Ciências. São oito físicos e seis químicos: Igor Tamm, Yakov Zeldovitch, Andrei Sakharov, Piotr Kapitza, Lev Landau, Evgenii Lifshits, Vitaly Ginzburg, Alexei Abrikosov, Nikolai Semenov, Yulii Beluusov, Anatol Jabotinsky, Alekandr Kitaigorodskii e Alexandr Nesmeyanov. Esta amostragem é significativa, abrangendo áreas nas quais a ciência soviética foi proeminente, como na física nuclear, física de baixas temperaturas e físicoquímica. Alguns desses cientistas foram seguidores fiéis do comunismo soviético (e alguns permaneceram leais a Stálin), enquanto outros emigraram posteriormente para os Estados Unidos. Sakharov, cujo prêmio Nobel foi na categoria da paz e não em seu campo da física, fez oposição à opressão política soviética, embora permanecesse acreditando nos ideais que formaram a União Soviética. O autor não esconde seus sentimentos contra o regime soviético, esquecendo que se a ascensão de Stálin foi acompanhada da irracionalidade do antissemitismo e da miséria dos campos de Gulag, nos Estados Unidos cientistas com inclinações esquerdistas como Linus Pauling e David Bohm enfrentaram muitas dificuldades.

Um ponto de convergência entre os cientistas soviéticos era sua convicção de que o poder da ciência soviética crescia. Os físicos e alguns dos químicos retratados trabalharam com problemas teóricos e práticos de 
explosivos e armas nucleares. De início, as potências ocidentais não acreditavam que os soviéticos seriam capazes de construir uma bomba atômica ou a ainda mais difícil bomba de hidrogênio. Os céticos se convenceram logo do contrário, como é sabido. Os sucessos soviéticos foram possíveis através dos esforços incessantes e patrioticamente motivados dos seus cientistas, homens e mulheres bem treinados motivados pela ameaça de destruição em massa. Logo depois de 1945 havia uma crença de que os Estados Unidos não hesitariam em jogar bombas nucleares em território soviético, como queria o matemático John von Neumann. Anos depois, até mesmo Sakharov ainda acreditava que manter o equilíbrio atômico era um pré-requisito para a paz entre as superpotências. Os cientistas que viveram a chamada Grande Guerra Patriótica contra a Alemanha nazista defendiam a necessidade de defender a pátria.

Mas o que aconteceu com a liderança científica depois do período soviético? Os cientistas que sobreviveram à Glasnost e à desintegração das repúblicas soviéticas já tinham vivido além do pico de suas carreiras produtivas. Com o pretexto da Perestroika, Gorbatchov e seus seguidores destruíram a economia sem substituí-la por algo que valesse a pena e a ciência foi uma das primeiras vítimas a cair na nova era. A educação científica, que tinha sido capaz de produzir tantos cientistas notáveis, também sofreu o declínio quando são cortados os gastos com ciência e cultura, como sabemos no Brasil contemporâneo.

Neste sentido, é instrutivo recordar a influência da ciência e técnica soviéticas no Ocidente durante o século XX foram influentes no Ocidente, como os projetos de aeronaves e helicópteros, com destaque para as pesquisas de Konstantin Tsiolkovsky com foguetes, que foram reconhecidamente uma grande contribuição para a construção de foguetes por Werner von Braun na Alemanha e, depois da Segunda Guerra, nos EUA. Pode-se citar também desenvolvimentos com semicondutores, lasers e teoria da informação (e também computadores), bem como a discussão sobre a origem da vida.

A tecnologia atômica teve um progresso espetacular, mas a geração nuclear de eletricidade foi feita de forma descuidada, deixando brechas de 
segurança, como é conhecido. A indústria aeroespacial russa (e ucraniana) deu bons resultados, que permitiram aperfeiçoamentos de grande alcance, inclusive a cooperação internacional permanente representada pelas estações espaciais. E o fuzil mais famoso desde o século XX tem sido, sem dúvida o AK-47, desenvolvido por Mikhail Kalashnikov, livremente copiado por dezenas de fabricantes de armas pelo mundo afora (com lucros enormes e sem remuneração ao país e inventor pelos direitos de cópia).

Além destes, há o campo importante dos fundamentos da biologia em que foram feitas descobertas impactantes como a do cientista Aleksandr Gurvitch, sobre a radiação mitogenética, gerada por ocasião da divisão celular, e cujos trabalhos depois de permanecerem em larga medida desconhecidos fora da Rússia, foram retomados nos últimos decênios por biofísicos alemães e outros. A simbiogênese foi reconsiderada por biólogos influentes como Lynn Margulis como fator determinante para explicar a evolução das espécies. Devese ainda assinalar a lenta, mas constante divulgação das concepções filosóficas de Vernadsky sobre a ciência como sendo a força geológica dominante na Terra, o que tem influenciado teorias sobre a expansão da noosfera humana pelo meio ambiente.

Para chegar a penetrar no âmago de questões realmente interessantes e relevantes como as que foram apresentadas neste breve panorama, seria muito saudável conhecer-se melhor a história da ciência soviética, com seus erros e acertos.

\section{Referências bibliográficas}

BAILES, Kendall. Science and Russian culture in an age of revolutions. V. I. Vernadsky and his scientific school, 1863-1945. Bloomington and Indianapolis: Indiana U. P., 1990

BAUER, Ervin - Theoretical biology. (Orig. Moscou, 1935). Budapest: Akadémiai Kiadó, 1982

BUKHARIN, Nikolai (ed.) Science at the crossroads. London: Frank Cass \& Co., 1931

Driesch, Hans - The science and philosophy of the organism: the Gifford Lectures. London: Adam \& Charles Black, 1908 
DUGATKIN, Lee e TRUT, Lyudmilla. How to tame a fox (and build a dog).Visionary scientists and a Siberian tale of jump-started evolution. Chicago: Chicago U. P., 2017

GRAHAM. Loren. Lonely ideas. Can Russia compete? Cambridge: MIT Press, 2013

GRAHAM, Loren. Lysenko's ghost. Epigenetics and Russia. Cambridge: Harvard U. P., 2016

GURVITCH, Alexander e GURVITCH, Lydia - "Twenty years of mitogenetic radiation: Emergence, development and perspectives" (orig. 1943), 21 ${ }^{\text {st }}$ Century, Fall 1999

HARGITTAI, Istvan. Buried glory. Portraits of soviet scientists. New York: Oxford U. P., 2013

HESSEN, Boris - "As raízes sócio-econômicas dos Principia de Newton", in Gama, Ruy (org.) Ciência e técnica. São Paulo: T.A. Queiroz, 1992

HUGHES, Thomas. American genesis. A century of invention and technological enthusiasm, 1870-1970. Chicago: Chicago U. P., 2004

KOJEVNIKOV, Alexei - "Freedom, collectivism, and quasiparticles: Social metaphors in quantum physics", Historical Studies in the Physical Sciences, 29:2 (1999)

KOJEVNIKOV, Alexei - "David Bohm and collective movement", Historical Studies in the Physical Sciences, 33:1 (2002)

KOJEVNIKOV, Alexei - "Lev Landau: physicist and revolutionary", Physics World, June 2002

KOJEVNIKOV. Alexei. Stalin's great science. The times and adventures of Soviet physicists. London: Imperial College Press, 2004

LÊNIN, V.I. Materialismo e Empiriocriticismo. Lisboa: Estampa, 1975

LIPKIND, Michael - "Alexander Gurwitsch and the concept of the biological field”, 21 ${ }^{\text {st }}$ Century; Part 1, summer 1998; Part 2, fall 1998

LYSENKO, T.D. - La situación en las ciencias biológicas. Moscou: Academia Lenin de Ciencias Agrícolas de la URSS/Sendero, 1948

MAGALHÃES, Gildo. "Ciência e ideologia na União Soviética". Simpósio Uma Jovem de 90 Anos (CD-ROM). USP, São Paulo, 2007 
MAKARENKO, Anton. Poema Pedagógico. São Paulo: Ed. 34, 2005

VERNADSKY, Vladimir Ivanovitch-Scientific thought as a planetary phenomenon, original de 1945 (resumido) e 1991(completo). Moscou: Fundação Ecológica Não-Governamental V. I. Vernadsky, 1997

VOEIKOV, Vladimir - "The scientific basis of the new biological paradigm", $21^{\text {st }}$ Century, Summer 1999 